\title{
RAÍZES SOCIAIS E IDEOLÓGICAS DO LULISMO
}

\author{
ANDRÉ SINGER
}

\section{RESUMO}

O artigo sugere hipóteses para compreender o realinhamento eleitoral que teria ocorrido em 2006 . O subproletariado, que sempre se manteve distante de Lula, aderiu em bloco à sua candidatura depois do primeiro mandato, ao mesmo tempo em que a classe média se afastou dela. A explicação estaria em uma nova configuração ideológica, que mistura elementos de esquerda e de direita. O discurso e a prática, que unem manutenção da estabilidade e ação distributiva do Estado, encontram-se na raiz da formação do lulismo.

PALAVRAS CHAVE: Realinhamento eleitoral; subproletariado; ideologia; lulismo.

\section{ABSTRACT}

This article suggests a few hypotheses to understand the new electoral configuration that was formed in 2006. The subproletariat, that has always kept itself away from Lula, accepted in large scale his candidature after the first term of his presidency, at the same time that the middle-class moved away from it. The explanation would be on a new ideological configuration, that mixes leftwing and rightwing elements. The rhetoric and the praxis, that are able to unite the maintenance of stability and the distributive action of the state, are in the origins of the formation of lulism.

KEYWORDS: New electoral configuration; subproletariat; ideology; lulism.

[1] No segundo turno de 2002 , Lula teve 52.788 .428 votos contra 33.366.430 votos para José Serra. No segundo turno de 2006, Lula ficou com 58.295 .042 votos, contra 37.543.178 votos para Geraldo Alckmin.
Talvez no futuro, quando for escrita a crônica factual dos dois mandatos presidenciais de Luiz Inácio Lula da Silva, o pleito de 29 de outubro de 2006 apareça como mera repetição dos resultados numéricos de quatro anos antes, em que o candidato do PT venceu o do PSDB por uma diferença em torno de 20 milhões de votos ${ }^{1}$. Remanescerá então encoberto, sob cifras quase idênticas, o deslocamento que, com o aspecto superficial da consagração do lulismo, pode ter significado, na verdade, um importante realinhamento político de estratos decisivos do eleitorado. 
A hipótese que desejamos sugerir neste artigo é que a emergência do lulismo expressa um fenômeno de representação de uma fração de classe que, embora majoritária, não consegue construir desde baixo as suas próprias formas de organização. Por isso, aos esforços despendidos até aqui para analisar a natureza do lulismo², achamos conveniente acrescentar a combinação de idéias que, a nosso ver, caracteriza a fração de classe que por ele seria representada: a expectativa de um Estado o suficientemente forte para diminuir a desigualdade, mas sem ameaçar a ordem estabelecida. Diante desse arranjo ideológico, uma possível nova hegemonia não seria "às avessas", como sugeriu Francisco de Oliveira, ainda que, ao juntar elementos de esquerda e de direita, cause a impressão de subverter a lógica dos argumentos3.

A percepção desse movimento profundo, que definiu a reeleição, foi dificultada porque ele se deu sem mobilização e "sem fazer-se notar", como assinalou um observador 4 . O silêncio provocou confusão à direita e à esquerda. Dez meses antes da reeleição, a revista Veja publicava que Lula seria derrotado porque, de acordo com pesquisa do Ibope, $40 \%$ do apoio obtido em 2002 tinha se esfumado e a "política assistencialista" não estava conseguindo segurar o eleitor de baixa renda. "A disputa eleitoral de verdade se dará entre Serra e Alckmin", escrevia Veja, mesmo avisando que previsões de longo prazo falhavam tanto quanto as meteorológicas 5 . Abertas as urnas, Oliveira ainda duvidava da "interpretação corrente" segundo a qual "o Brasil eleitoral se dividiu entre pobres e ricos". "Seria ótimo, se fosse plausível que os $40 \%$ de votos de Alckmin foram dos 'ricos', e que a votação de Lula foi exclusivamente dos 'pobres'”, escreveu Oliveira sobre o primeiro turno ${ }^{6}$.

A origem do mal-entendido é dupla. De um lado, houve um deslocamento subterrâneo de eleitores não de baixa renda, mas de baixíssima renda, o qual passou despercebido, de outro, porque se deu de modo concomitante ao estardalhaço em torno do "mensalão", escândalo que teceu, a partir de maio de 2005 , um cerco político-midiático ao presidente, deixando-o na defensiva por cerca de seis meses ${ }^{7}$. No período do "mensalão", o governo efetivamente perdeu parcela importante do suporte que trazia desde a eleição de 2002 . Nas camadas médias, essa rejeição desdobrou-se numa forte preferência por um candidato de oposição à presidência em 2006 . "Entre os brasileiros de escolaridade superior, a reprovação a Lula deu um salto de 16 pontos percentuais, passando de $24 \%$ em agosto para $40 \%$ hoje", escrevia a Folha de S.Paulo em 23 de outubro de 2005 . Três meses depois, porém, enquanto os mais ricos, seguindo na linha anterior, optavam em massa (65\%) pelo então pré-candidato do PSDB, entre os de renda familiar de até cinco salários mínimos ocorria uma inflexão, com um aumento dos índices de satisfação a respeito do mandato de Lula ${ }^{8}$. Sobretudo no fundo da
[2] Ver, por exemplo, Viana, Gilney. "O PT e o lulismo", 2007, <www. pt.org.br>, acessado em 25/08/2009; Simões, Renato. "Duas agendas: na crise, de duas, uma", 2009, <www. pt.org.br>, acessado em 25/08/2009. Em outra vertente, e de modo mais ligeiro, ver a menção ao lulismo na entrevista de Carlos Augusto Montenegro ao jornal Valor, 23/09/2009, intitulada "Identificação ao PT derrota Dilma”.

[3] Ver Oliveira, Francisco de. "Hegemonia às avessas". Piauí, $\mathrm{n}^{\mathrm{o}} 7$, jan. 2007.

[4] Amaral, Roberto. "As eleições de 2006 e as massas: uma emergência frustrada?" 'www.psbnacional.org. br>, acessado em 25/08/2009.

[5] Veja, $\mathrm{n}^{\circ} 1936,21 / 12 / 2005$, p. 55: "De agosto para cá, segundo o Ibope, Lula perdeu 9 pontos porcentuais entre aqueles que, até a eclosão da crise, eram seus eleitores mais fiéis: brasileiros que ganham até um salário mínimo".

[6] Oliveira, op. cit. No primeiro turno de 2006 , que ocorreu a primeiro de outubro, Lula teve 46.662 .365 votos e Geraldo Alckmin, 39.968.369, Heloísa Helena, 6.575.393 e Cristovam Buarque, 2.538.544.

[7] Usando balizamentos de mídia, pode-se dizer que a fase aguda do "mensalão" iniciou-se com a reportagem de Veja que começou a circular em 14 de maio de 2005 e terminou com a entrevista presidencial ao programa Roda Viva, da TV Cultura de São Paulo, em 7 de novembro do mesmo ano.

[8] Folha de S. Paulo, 5/02/2006. 


\begin{tabular}{|c|c|c|c|c|c|}
\hline & Até 2 SM & + de 2 a 5 SM & + de 5 a 10 SM & + de $10 \mathrm{SM}$ & Total \\
\hline Lula & $55 \%$ & $41 \%$ & $30 \%$ & $29 \%$ & $45 \%$ \\
\hline Alckmin & $28 \%$ & $38 \%$ & $45 \%$ & $44 \%$ & $34 \%$ \\
\hline Heloisa Helena & $6 \%$ & $9 \%$ & $14 \%$ & $11 \%$ & $9 \%$ \\
\hline Cristovam & $1 \%$ & $3 \%$ & $4 \%$ & $5 \%$ & $2 \%$ \\
\hline Outros & $1 \%$ & $1 \%$ & $0,3 \%$ & $2 \%$ & $1 \%$ \\
\hline $\mathrm{BR} / \mathrm{Nulo} /$ Indecisos & $8 \%$ & $9 \%$ & $7 \%$ & $9 \%$ & $9 \%$ \\
\hline Total & $100 \%$ & $100 \%$ & $100 \%$ & $100 \%$ & $100 \%$ \\
\hline
\end{tabular}

Fonte: Ibope. Pesquisa com amostra nacional de 3010 eleitores, realizada entre 28 e 30 de setembro de 2006.

TABELA 2

Intenção de voto por renda no $2^{\circ}$ turno de 2006

\begin{tabular}{l|c|c|c|c|c}
\hline & Até 2 SM & + de 2 a 5 SM & + de 5 a I0 SM & + de I0 SM & Total \\
\hline Lula & $64 \%$ & $56 \%$ & $44 \%$ & $36 \%$ & $57 \%$ \\
Alckmin & $25 \%$ & $35 \%$ & $46 \%$ & $54 \%$ & $33 \%$ \\
Br/Nulo/Não sabe/Não opinou & $10 \%$ & $9 \%$ & $11 \%$ & $10 \%$ & $10 \%$ \\
Total & $100 \%$ & $100 \%$ & $100 \%$ & $100 \%$ & $100 \%$ \\
\hline
\end{tabular}

Fonte: Ibope. Pesquisa com amostra nacional de 8680 eleitores, realizada entre 26 e 28 de outubro de 2006.

[9] Ver resultados das pesquisas Datafolha nas edições da Folha de $S$. Paulo de 23/11/2005 e 5/02/2006.

[10] Agradeço ao Centro de Estudos de Opinião Pública da Unicamp a cessão de dados do Ibope/2006 utilizados neste artigo e a Gustavo Venturi a cessão de dados da Fundação Perseu Abramo. sociedade, onde circulam personagens de escassa visibilidade, houve uma crescente inclinação, desde pelo menos o início de 2006, no sentido de manter no Palácio do Planalto o ex-retirante pernambucano que tinha as mesmas origens dos seus recém-apoiadores?.

A divergência entre os estratos de renda irá crescer ao longo de 2006, eos números encontrados pelo Ibope perto do primeiro e do segundo turnos expressam uma disputa socialmente polarizada, como mostram as Tabelas 1 e $2^{10}$. Nelas, a disposição de sufragar em Lula da parcela mais pobre inverte-se de maneira linear à medida que aumenta o rendimento, de modo que os mais ricos dão folgada maioria a Alckmin. O que atrapalhou a compreensão elevou analistas como Oliveira a considerarem pouco plausível que os quase 40 milhões de votos em Alckmin no primeiro turno fossem apenas dos "ricos" é a dualidade brasileira, que grosso modo transforma em "classe média" todos (aí incluídos setores assalariados de baixa renda) os que não pertencem à metade da população que tem baixíssima renda. Lula foi eleito, sobretudo, pelo apoio que teve no segmento de baixíssima renda, enquanto 
Alckmin contou, além do voto dos mais ricos, com certa sustentação na fatia de eleitores de classe média baixa, que vagamente corresponde ao que os especialistas de mercado chamam de "classe C". Na faixa de mais de dois a cinco salários mínimos de renda familiar mensal, por exemplo, Alckmin quase empatava com Lula às vésperas do primeiro turno (Tabela 1), mas entre os eleitores de baixíssima renda (até dois salários mínimos de renda familiar mensal), Lula aparecia com uma vantagem de 26 pontos percentuais sobre Alckmin. Por isso, é verdadeira a interpretação de que o Brasil eleitoral se dividiu entre pobres e ricos. A polarização social do pleito deu-se pela implantação de Lula entre os eleitores de baixíssima renda, visível desde o primeiro turno, assim como a de Alckmin, entre os eleitores de renda mais alta (acima de dez salários mínimos de renda familiar mensal).

Os dados mostram que o lulismo foi expressão de uma camada social específica, e o descolamento entre eleitores de baixíssima renda e de "classe média", que apareceu nos debates pós-eleitorais sob a forma de "questionamento do real papel dos chamados 'formadores de opinião" "11, outorgou um caráter único à eleição de 2006 . Em perspectiva comparada, as cientistas políticas Denilde Oliveira Holzhacker e Elizabeth Balbachevsky observaram que em 2002 o voto em Lula "não estava especialmente associado com nenhum estrato social", enquanto em 2006 "os eleitores de classe baixa se mostram significativamente mais inclinados a dar seu voto a Lula" ${ }^{12}$. Na realidade, o único caso anterior de polarização por renda em eleições presidenciais, desde a redemocratização, surgira no segundo turno de 1989, sendo que naquela ocasião a candidatura Lula estava, não por acaso, no lado oposto da linha que dividia pobres e ricos, como notaram Wendy Hunter e Thimoty J. Power'3 ${ }^{13}$ Enquanto Fernando Collor de Mello alcançava vantagem de dez pontos percentuais na faixa de eleitores que recebiam até dois salários mínimos de renda familiar mensal, no segmento mais alto quem obtinha essa vantagem era Lula (Tabela 3 ).
[11]Amaral, op. cit., p. 9.

\begin{abstract}
[12] Holzhacker, Denilde e Balbachevsky, Elizabeth. "Classe, ideologia e política: uma interpretação dos resultados das eleições de $2002 \mathrm{e}$ 2006". Opinião Pública, vol. 13, ${ }^{\circ} 2$, nov. 2007, pp. 294-96.
\end{abstract}

[13] Hunter, Wendy e Power, Thimoty J. "Rewarding Lula: executive power, social policy, and the brazilian elections of 2006 ". Latin American Politics and Society, vol. $49, \mathrm{n}^{\circ}$ 1, 2007, p. 4 .

\begin{tabular}{l|c|c|c|c}
\hline & Até 2 SM & + de 2 a 5 SM & + de 5 a 10 SM & + de 10 SM \\
\cline { 2 - 3 } Collor & $51 \%$ & $43 \%$ & $40 \%$ & $40 \%$ \\
Lula & $41 \%$ & $49 \%$ & $51 \%$ & $52 \%$ \\
Nenhum/BR/Nulo/Não sabe/Não opinou & $8 \%$ & $8 \%$ & $9 \%$ & $8 \%$ \\
Total & $100 \%$ & $100 \%$ & $100 \%$ & $100 \%$ \\
\hline
\end{tabular}


[14] Singer, André. "Collor na periferia: a volta por cima do populismo?". In: Lamounier, B. (org.), De Geisel a Collor, o balanço da transição. São Paulo: Sumaré, 1990, p. 138.

[15] Idem. Sem medo de ser feliz. São Paulo: Scritta, 1990, pp. 98-99.

[16] Ibidem, p. 98 .

[17] Sobre os dados que evidenciam a adesão intuitiva à direita, ver Singer, A. Esquerda e direita no eleitorado brasileiro. São Paulo: Edusp, 2000.
Se no primeiro turno de 1989 já havia uma nítida tendência de crescimento do apoio a Collor com a queda da renda, levando a uma concentração do voto nele entre os mais pobres, no campo oposto ("classe média") ocorria uma dispersão de votos entre Lula, Brizola, Covas e Maluf, não caracterizando, ainda, a polarização, que viria a ocorrer no segundo turno ${ }^{14}$. Em entrevista concedida depois daquele pleito, Lula afirmava:

A verdade nua crua éque quem nos derrotou, além dos meios de comunicação,foram os setores menos esclarecidos e mais desfavorecidos da sociedade [...]. Nós temos amplos setores da classe média com a gente - uma parcela muito grande do funcionalismo público, dos intelectuais, dos estudantes, do pessoal organizado em sindicatos, do chamado setormédio da classe trabalhadora ${ }^{15}$.

Consciente do peso eleitoral dos "mais desfavorecidos", ele acrescentava:

A minha briga é sempre esta: atingir o segmento da sociedade que ganha salário mínimo. Tem uma parcela da sociedade que é ideologicamente contra nós, e não há porque perder tempo com ela:não adianta tentar convencer um empresário que écontra o Lula a ficar do lado do trabalhador. Nós temos que ir para a periferia, onde estão milhões de pessoas que se deixam seduzir pela promessa fácil de casa e comida ${ }^{16}$.

Em trabalhos sobre a eleição de 1989 , notei, entretanto, que a vitória de Collor não decorria apenas de promessas fáceis. Havia uma hostilidade às greves, cuja onda ascensional se prolongou desde 1978 até as vésperas da primeira eleição direta para presidente, e da qual Lula era, então, o símbolo maior. Observava-se um aumento linear da concordância com o uso de tropas para acabar com as greves conforme declinava a renda do entrevistado, indo de um mínimo de $8,6 \%$, entre os que tinham renda familiar acima de vinte salários mínimos, a um máximo de 41,6\% entre os que pertenciam a famílias cujo ingresso era de apenas dois salários mínimos (Tabela 4). Em outras palavras, ao contrário do esperado, os mais pobres eram mais hostis às greves do que os mais ricos. Em parte, é essa inversão que faz a nova hegemonia parecer "às avessas".

Àépoca, assinalamos que a resistência às greves è̀ candidatura Lula, manifestada por eleitores de baixíssima renda, estava associada, além do mais, a uma autolocalização intuitiva à direita do espectro ideológico ${ }^{17}$. Não obstante, tratava-se de uma direita peculiar, uma vez que favorável à intervenção do Estado na economia, como se podever na Tabela 5. Como resolver a aparente contradição? Sugerimos a interpretação de que os eleitores mais pobres buscariam uma redução da desigualdade, da qual teriam consciência, por meio de uma intervenção direta do Estado, evitando movimentos sociais que pudessem desestabilizar a ordem. 


\begin{tabular}{|c|c|c|c|c|c|c|}
\hline & Até 2 SM & + de 2 a 5 SM & + de 5 a 10 SM & + de IO SM & + de 20 SM & Total \\
\hline Concorda & $41,6 \%$ & $24,3 \%$ & $15,7 \%$ & $15,7 \%$ & $8,6 \%$ & $25,7 \%$ \\
\hline Discorda & $49,2 \%$ & $63,9 \%$ & $72,1 \%$ & $70,1 \%$ & $73,6 \%$ & $62,5 \%$ \\
\hline Depende & $4,4 \%$ & $8,1 \%$ & $9,7 \%$ & $13,4 \%$ & $13,4 \%$ & $8,4 \%$ \\
\hline Não sabe & $4,8 \%$ & $3,7 \%$ & $2,5 \%$ & $0,7 \%$ & $4,3 \%$ & $3,5 \%$ \\
\hline Total & $100 \%$ & $100 \%$ & $100 \%$ & $100 \%$ & $100 \%$ & $100 \%$ \\
\hline
\end{tabular}

Fonte: Cultura Política (Consórcio USP/Cedec/Datafolha). Pesquisa realizada com amostra nacional de 2480 eleitores, realizada em março de 1990, conforme André Singer, Ideologia e voto no segundo turno da eleição presidencial de 1989. São Paulo, Dissertação de Mestrado, 1993, p. 71.

TABELA 5

Reconhecimento de que o governo deve intervir mais na economia por autolocalização na escala esquerdadireta, 1993

\begin{tabular}{|c|c|c|c|c|c|c|c|c|c|c|c|}
\hline & Esq. & 2 & 3 & 4 & 5 & 6 & 7 & 8 & 9 & Dir. & Total \\
\hline Concorda (1) & $59,7 \%$ & $58,9 \%$ & $59,0 \%$ & $43,7 \%$ & $42,2 \%$ & $50,9 \%$ & $61,3 \%$ & $64,4 \%$ & $67,4 \%$ & $68,1 \%$ & $57,4 \%$ \\
\hline (2) & $11,2 \%$ & $15,0 \%$ & $13,8 \%$ & $18,2 \%$ & $20,0 \%$ & $20,6 \%$ & $18,1 \%$ & $15,6 \%$ & $16,2 \%$ & $12,6 \%$ & $16,6 \%$ \\
\hline (3) & $3,4 \%$ & $8,7 \%$ & $8,6 \%$ & $12,4 \%$ & $6,9 \%$ & $8,6 \%$ & $3,8 \%$ & $5,9 \%$ & $6,5 \%$ & $2,3 \%$ & $6,6 \%$ \\
\hline Discorda (4) & $25,8 \%$ & $17,5 \%$ & $18,5 \%$ & $25,7 \%$ & $30,9 \%$ & $19,9 \%$ & $16,8 \%$ & $14,0 \%$ & $9,9 \%$ & $17,1 \%$ & $19,5 \%$ \\
\hline Total & $100 \%$ & $100 \%$ & $100 \%$ & $100 \%$ & $100 \%$ & $100 \%$ & $100 \%$ & $100 \%$ & $100 \%$ & $100 \%$ & $100 \%$ \\
\hline
\end{tabular}

Fonte: Cultura Política (Consórcio USP/Cedec/Datafolha), pesquisa com amostra nacional de 2499 eleitores realizada em março de 1993, conforme André Singer, Esquerda e direita no eleitorado brasileiro. São Paulo, Edusp, 2000, página 188 .

Para eleitores de menor renda, a clivagem entre esquerda e direita não estaria em ser contra ou a favor da redução da desigualdade e sim em como obtê-la. Identificada como opção que colocava a ordem em risco, a esquerda era preterida em favor de uma solução pelo alto, de uma autoridade já constituída que pudesse proteger os mais pobres sem ameaça de instabilidade. Esse seria o sentido da adesão intuitiva à direita (muitas vezes entendida como o que é direito ou como sinônimo de governo versus oposição) no espectro ideológico e tornaria inteligível o viés desfavorável a Lula.

O modelo de comportamento político desenhado acima tem antecedentes clássicos. Marx, em O 18 Brumário de Luís Bonaparte ${ }^{18}$, revela que a projeção de anseios em uma força previamente existente, que deriva da necessidade de ser constituído como ator político desde o alto, [18] Marx, Karl. O 18 Brumário de Luís Bonaparte. São Paulo: Paz e Terra, 1986 , p. 116. é típica de classes ou frações de classe que têm dificuldades estruturais para se organizar. A natureza do vínculo esclarece por que o seu surgi- 
[19] Ibidem.

[20] Mendes, Antonio Manuel Teixeira e Venturi, Gustavo. "Eleição presidencial: o Plano Real na sucessão de Itamar Franco". Opinião Pública, vol. 2, no 2 , dez. 1994, pp. 43-45. mento sempre causa surpresa. Como eles "não podem representar-se, antes têm que ser representados"19, aparecem na política como raio em céu azul, uma vez que surgem de cima para baixo, sem aviso prévio, sem a mobilização lenta (e barulhenta) que caracteriza a auto-organização autônoma das classes subalternas quando ela se dá nos moldes típicos do século XIX, isto é, dos partidos e movimentos de classe.

O fato de Collor ter decepcionado a base social que o elegeu ao provocar a recessão de 1990/1991, levando à perda de suporte que facilitou o impedimento em 1992, não mudou a estrutura de comportamento político que o pleito de 1989 iluminara. Em 1994 e 1998, o "conservadorismo popular", acionado pela inflação e pelo medo da instabilidade, venceu Lula outra vez. Era relativamente claro que havia um poder de veto das classes dominantes, o qual residia na capacidade de mobilizar o voto de baixíssima renda. O que não se distinguia com nitidez eram as raízes ideológicas do mecanismo, embora os levantamentos de opinião indicassem permanente supremacia conservadora na distribuição do eleitorado entre esquerda e direita. O campo da direita aparecia sempre tendo uma adesão $50 \%$ superior ao da esquerda, como se observa no Quadro 1, desequilíbrio que decorria da inclinação dos eleitores de menor renda para a direita.

Nesse sentido, as derrotas de Lula em 1994 e 1998 podem ser entendidas como reedições de 1989 , apesar da estabilidade monetária ter se sobreposto, em 1994, aos argumentos abertamente ideológicos utilizados por Collor (ameaça comunista) em 1989. Tal como em 1989, as duas campanhas de Fernando Henrique Cardoso mobilizaram os eleitores de menor renda contra a esquerda. Antonio Manuel Teixeira Mendes e Gustavo Venturi demonstraram que, na esteira do Plano Real, o melhor resultado de Lula em 1994 ocorreu entre os estudantes, entre os assalariados registrados com escolaridade secundária ou superior e entre os funcionários públicos. Já os trabalhadores sem registro formal, portanto, desvinculados da organização sindical, deram os melhores resultados a Fernando Henrique 20 . Em 1998, a coligação

QUADROI

Posição no espectro ideológico (Brasil), 1989-2006

\begin{tabular}{l|c|c|c|c} 
& Esquerda & Centro & Direita & NS/NR \\
\cline { 2 - 2 } 1989 (Datafolha, set. 89) & $22 \%$ & $19 \%$ & $37 \%$ & $20 \%$ \\
1997 (F. Perseu Abramo, nov. 97) & $19 \%$ & $21 \%$ & $34 \%$ & $25 \%$ \\
2002 (Criterium, out. 02) & $26 \%$ & $18 \%$ & $18 \%$ & $16 \%$ \\
2006 (F. Perseu Abramo, mar. 06) & $26 \%$ & $20 \%$ & $40 \%$ & $14 \%$ \\
\hline
\end{tabular}

Obs.: As posições na escala de 1 a 7 foram assim agrupadas: esquerda $=1$ a 3 ; centro $=4$; direita $=5$ a 7 . Fonte: Fundação Perseu Abramo, conforme «www2.fpa.org.br), consultado em 18/9/2009. 
vencedora procurou convencer, com sucesso, os eleitores mais pobres de que Cardoso seria o melhor condutor do país em meio à crise financeira internacional que ameaçava a estabilidade conquistada quatro anos antes ${ }^{21}$. De acordo com Tarso Genro, "boa parte das massas excluídas simplesmente repercutiram esta estratégia manipuladora" [...]. Para Genro, em 1998 "pesou significativamente, mais do que ocorreu com a eleição de Collor, uma grande parte da população marginalizada, lumpesinada ou meramente excluída do mundo da Lei e do Direito"22. Em decorrência, os argumentos da campanha de Lula de que Fernando Henrique tinha abaixado "a cabeça para os banqueirose agiotas internacionais [...], aumentou os juros [...] e as empresas estão fechando e demitindo" 23 não atraíram mais do que os cerca de $30 \%$ de votos válidos que pareciam, então, constituir o teto do candidato, quando, na realidade, eram o teto da esquerda, socialmente limitada pela rejeição do subproletariado no extremo inferior de renda.

Mesmo em 2002, depois de unir-se a um partido de centro-direita, anunciar um candidato a vice de extração empresarial, assinar uma carta-compromisso com garantias ao capital e declarar-se o candidato da paz e do amor, Lula tinha menos intenção de voto entre os eleitores de renda mais baixa do que entre os de renda superior. Hunter e Power notaram corretamente que "que em suas quatro corridas presidenciais entre 1989 e 2002 , a principal base de apoio a Lula estava entre os eleitores dos níveis superiores de escolarização nos Estados mais urbanizados e industrializados do Sul e do Sudeste" 24 . Em suma, a base social de Lula e do PT expressavam as características da esquerda em uma nação cuja metade mais pobre pendia para a direita.

Só depois de assumir o governo, Lula obteve a adesão do segmento de classe que buscava desde pelo menos 1989. "Lula perdeu intenções e, provavelmente, votos entre alguns de seus eleitores 'tradicionais', 'decepcionados' com os 'escândalos'. Substituiu-os, porém, e compensou as perdas, com votos de 'não-eleitores', pessoas que nunca haviam votado nele antes", afirma Marcos Coimbra, diretor do Instituto Vox Populi25. Entre a eleição de 2002 , comemorada como sendo a da demorada ascensão da esquerda em país de tradição conservadora, e a reeleição de Lula por outra base social e ideológica, em outubro de 2006 , operou-se uma transformação que se faz necessário entender.

\section{AS BASES MATERIAIS DO REALINHAMENTO}

[...] as primeiras pesquisas feitas logo após o começo do governo captaram uma nítida mudança nas atitudes dos eleitores de classe popular, apontando para o aumento de sua auto-estima e da confiança, de que o Brasil iria melhorar, agora que as políticas de governo passariam a ter outra intenção e finalidades:um governo diferente, com gente diferente, fazendo coisas diferentes ${ }^{26}$.
[21] “Muitos votaram pela reeleição porque Fernando Henrique Cardoso tinha apoio internacional, do qual Lula carecia" (Singer, Paul. "No olho do furacão". Teoria e Debate, $\mathrm{n}^{\circ} 39$, out.-dez.1998, p. 22).

[22] Genro, Tarso. "Um confronto desigual e combinado". Teoria e Deba$t e, \mathrm{n}^{\circ} 39$, out.-dez. 1998 , p. 5 .

[23] Almeida, Jorge. Marketing político, hegemonia e contra-hegemonia. São Paulo: Fundação Perseu Abramo, 2002, p. 219.

[24] Hunter e Power, op. cit., p. 4. Tradução minha (AS).

[25] Coimbra, Marcos. "Quatro razões para a vitória de Lula". Cadernos Fórum Nacional, n ${ }^{\circ}$ 6, fev. 2007, p. 7, grifos meus.

[26] Ibidem, p. 13 . 
[27] Ibidem, p.11.

[28] Sobre o crescimento do Programa Bolsa Família, ver Nicolau, Jairo e Peixoto, Vitor. "As bases municipais da votação de Lula em 2006". Cadernos Fórum Nacional, $\mathrm{n}^{\circ}$ 6, fev. 2007 , p. 20; Araújo, José Prata. Um retrato do Brasil. São Paulo: Fundação Perseu Abramo, 2006, p. 155.

[29] Licio, Elaine Cristina, Rennó, Lucio R.e Castro, Henrique Carlos de O. de. "Bolsa Família e voto na eleição presidencial de 2006: em busca do elo perdido". Opinião Pública, vol. $15, \mathrm{n}^{\circ} 1$, jun. 2009 , p. 43.

[30] Carreirão, Yan de Souza. "Evolução das opiniões do eleitorado durante o governo Lula e as eleições presidenciais brasileiras de 2006", 2007, 〈www.waporcolonia.com〉, acessado em30/08/2009.

[31] Nicolau e Peixoto, op. cit., p. 21.
Mas só três anos depois da posseem primeiro de janeiro de 2003 , quando outro pleito já apontava no horizonte, é que tais "mudanças nas atitudes" se expressaram na forma de uma adesão que salvou o presidente da morte política a que parecia condenado pela rejeição da classe média.

Uma explicação para esse lapso de tempo emana da própria análise de Coimbra. De acordo com ela, o "fundamento" da aprovação ao governo, que por sua vez levou ao voto em Lula em 2006, "foi a sensação de eleitores de renda baixa e média de que o seu poder de consumo aumentara, seja em produtos tradicionais (alimentos, material de construção), seja em novos (celulares, DVDs, passagens aéreas)" 27. Essa "sensação" não caberia no começo do mandato, marcado por política econômica recessiva. No entanto, a partir do final de 2003 , com o lançamento do Programa Bolsa Família (PBF), inicia-se uma gradual melhora na condição de vida dos mais pobres. No princípio apenas unificação de programas de transferência de renda herdados da administração Fernando Henrique, o qual, por sua vez, copiara a fórmula de governos petistas, aos poucos a quantidade de recursos destinados ao PBF o converteu em uma espécie de renda mínima para todas as famílias brasileiras que comprovassem situação de extrema necessidade. Em 2004, o PBF recebeu verba 64\% maior e, em 2005, ano do "mensalão", teve um aumento de outros $26 \%$, mais do que duplicando o número de famílias atendidas, de 3,6 milhões para 8,7 milhões, em dois anos. Entre 2003 e 2006, a Bolsa Família viu o seu orçamento multiplicado por treze, pulando de $\mathrm{R} \$ 570$ milhões de reais para 7,5 bilhões de reais, atendendo a cerca de 11,4 milhões de famílias perto da eleição de $2006^{28}$.

Diversos estudos encontraram indícios de queo PBF teve influência nos votos recebidos por Lula em 2006. Elaine Cristina Licio e colaboradores verificaram, por meio de survey, "no que se refere à atitude dos beneficiários do Programa", que "a porcentagem de voto em Lula foi cerca de 15\% maior no primeiro e segundo turnos" em comparação com a obtida na média do eleitorado 29 . Em segundo lugar, Yan de Souza Carreirão relaciona a alta votação de Lula nas regiões nordeste e norte com o fato de o programa ter-se concentrado naquelas áreas. Lula teve, no primeiro turno, por exemplo, cerca de $60 \%$ de votos no Nordeste e apenas $33 \%$ no Sul, sendo que o investimento do $\mathrm{PBF}$ na primeira região foi três vezes maior do que na segunda ${ }^{\circ}$. Em observação mais segmentada, Nicolau e Peixoto notaram que "Lula obteve percentualmente mais votos nos municípios que receberam mais recursos per capita do Bolsa Família"31, mostrando a repercussão do programa nos chamados grotões, tipicamente o interior do Norte/Nordeste, que sempre fora tradicional território do conservadorismo. Por fim, vale notar que, de acordo com Coimbra, entre 
os que votaram em Lula pela primeira vez em 2006, a maioria eram mulheres de renda baixa, "o público alvo por excelência do Bolsa Família", pois em geral são as mães que recebem o benefício32.

Assim, soa consistente a afirmação de que o PBF cumpriu um papel na vitória de Lula. Porém, "a importância do Bolsa Família não deve ser subestimada e nem exagerada", adverte Coimbra. "Sozinho não bastaria para explicar o resultado da eleição" 33, diz o diretor do Vox Populi.Cláudio Djissei Shikida e colaboradores argumentam que raciocínios centrados no local de votação correm o risco de apenas mostrar a coincidência geográfica de dois fatores, a saber, a presença do PBF, dada a pobreza do lugar, e o voto em Lula, mas não a sua relação causal.A Bolsa Família foi obviamente destinada em maior proporção às regiões pobres e aos municípios de menor IDH. Mas o fato de a votação em Lula ter sido maior nessas regiões e municípios não implica que ela fosse causada pelo PBF ou só por ele. Fazendo uso de outro instrumental estatístico para compulsar as tendências municipais, Shikida e colaboradores concluem:

OPBF mostrou alguma evidência de impacto positivo na eleição, porém os resultados não se mostraram robustos. Mesmo se significativo fosse, o valor do estimador seria bem menor do que o necessário para que essa fosse a variável-chave para a compreensão da eleição de Lula.34

Shikida e colaboradores sugerem que o controle dos preços, como um componente central do aumento do poder de compra entre as camadas pobres, pudesse ser mais explicativo da virada ocorrida em 2006. Chamam a atenção, por exemplo, para o fato de que entre 2003 e 2006 , a cesta básica subiu 8,5\% e 10,4\% em Porto Alegre e São Paulo, mas, em Recife e Fortaleza, a variação foi de 4\% e de -3\%. Terá sido coincidência Lula ter perdido no Rio Grande do Sul eem São Paulo nos dois turnos, ao passo que no Estado de Pernambuco recebeu $82 \%$ dos votos no segundo turno e no Ceará, 75\%35?

$\mathrm{Na}$ mesma linha, de mirar além da Bolsa Família, Hunter e Power lembram que o aumento real de 24,25\% no salário mínimo durante o primeiro mandato teve um impacto mais abrangente do que o PBF. Além disso, a Bolsa Família e a elevação do salário mínimo, somadas, dinamizaram as economias locais menos desenvolvidas,

\section{[...] que dependem pesadamente de despesas pessoais de pequena es-} cala para o seu sustento. Assim, não é surpreendente que as vendas do varejo tenham subido dramaticamente nos últimos três anos no norte e nordeste do Brasil [...]. Também não é surpreendente que essas sejam as duas regiões nas quais o comparecimento eleitoral e o apoio a Lula tenham crescido em 2006 comparado a $2002^{36}$.
[32] Coimbra, op. cit., p. 7.

[33] Idem, ibidem.

[35] Idem, ibidem.

[36] Hunter e Power, op. cit., p. 16, trad. minha. 
[37] Carreirão, op.cit.

[38 Neri, Marcelo. "Miséria, desigualdade e políticas de renda: o Real do Lula", 2007, 〈www3.fgv.br〉, acessado em 30/08/2009.
O primeiro aumento importante do salário mínimo ocorreu em maio de 2005 , eé razoável imaginar que a poderosa combinação Bolsa Família-salário mínimo tenha demorado alguns meses para produzir efeitos. Mas além do aumento obtido pelos milhões que recebem um salário mínimo da Previdência Social, outra possibilidade aberta aos aposentados, às vezes principal fonte de recursos em pequenas comunidades, foi o uso do crédito consignado. O crédito consignado fez parte de uma série de iniciativas oficiais que tinha por objetivo expandir o financiamento popular, que incluiu um aumento expressivo do empréstimo à agricultura familiar, do microcrédito e da bancarização de pessoas de baixíssima renda.

Criado em 2004, o crédito consignado permitiu aos bancos descontar empréstimos em parcelas mensais retiradas diretamente da folha de pagamentos do assalariado ou do aposentado. A redução do risco decorrente do pagamento garantido acarretou uma queda em quase treze pontos percentuais da taxa de juros, e, em 2005, depois de crescer quase $80 \%$, o crédito consignado colocava em circulação dezenas de bilhões de reais, usados, em geral, para o consumo popular.Ainda no capítulo da assistência social, com a promulgação do Estatuto de Idoso, em janeiro de 2004 , a idade mínima para receber o Benefício de Prestação Continuada (BPC), que paga um salário mínimo para idosos ou portadores de necessidades es peciais cuja renda familiar per capita seja inferior a $1 \frac{1}{4}$ de salário mínimo, caiu de 67 para 65 anos. Em 2006, 2,4 milhões de cidadãos recebiam o BPC.

Além dessas medidas de alcance geral, que propiciaram a ativação de setores antes inexistentes na economia (por exemplo, clínicas dentárias para a baixa renda), uma série de programas focalizados, como o Luz para Todos (de eletrificação rural), regularização das propriedades quilombolas, construção de cisternas no semi-árido etc. favoreceram o setor de baixíssima renda. Carreirão reproduz um cruzamento realizado pelo Datafolha em junho de 2006, que mostra a influência de ser atendido por programa governamental sobre a disposição de reeleger o presidente. Os números mostram que a intenção de voto em Lula pulava de $39 \%$, na média, para 62\%, quando o entrevistado participava de algum programa federal37.

O tripé formado pela Bolsa Família, pelo salário mínimo e pela expansão do crédito, somado aos referidos programas específicos, resultaram em uma diminuição significativa da pobreza a partir de 2004, quando a economia voltou a crescere o emprego a aumentar.É isso que Marcelo Neri chama de "o Real de Lula": "No biênio 1993-1995 a proporção de pessoas abaixo da linha da miséria cai $18,47 \%$ e, no período 2003-2005, a mesma cai 19,18\%"38.

Emparticularnoanode2005, quandoeclodiuoescândalodo "mensalão", ocorreu, segundo classificação de Waldir Quadros, a primeira 
redução significativa da miséria desde o Plano Real ${ }^{39}$, presumivelmente em conseqüência do conjunto de medidas tomadas pelo governo Lula. Assim, enquanto os atores políticos tinham a atenção voltada para a seqüência de denúncias do "mensalão", o governo produzia em silêncio o "Real do Lula" que, diferentemente do original, beneficiava, sobretudo, a camada da sociedade que não aparece nas revistas.

\section{FRAÇÃO DE CLASSE E IDEOLOGIA}

Examinadas em seu conjunto, as ações governamentais do primeiro mandato vão muito além de simples "ajuda" aos pobres. Sem falar nos programas específicos, o aumento do salário mínimo, a expansão do crédito popular com aumento da formalização do trabalho (o desemprego caiu de 10,5\% em dezembro de 2002 para $8,3 \% \mathrm{em}$ dezembro de 2005$)^{40}$ e a transferência de renda, aliados à contenção de preços, sobretudo da cesta básica (eem alguns casos deflação, como decorrência da desoneração fiscal), constituem uma plataforma no sentido de traçar uma direção política para os anseios de certa fração de classe. Não apenas porque objetivamente foram capazes de aumentar a capacidade de consumo de milhões de pessoas de baixíssima renda, como atesta o acesso em grande escala à "classe C", mas também porque sugerem um caminho a seguir: manutenção da estabilidade com expansão do mercado interno, sobretudo para os setores de baixa renda. Nesse sentido, tais ações colocam Lula à frente de um projeto, que é compatível com aspectos de sua biografia.

Coimbra, orientador de diversas pesquisas quantitativas e qualitativas no período, chama a atenção para o fato de Lula ser o político de origem mais humilde a ter chegado ao topo do sistema, assim como para o fato de "a intensa campanha negativa que sofreu em suas tentativas anteriores" ter feito dele alguém que mexeu com a "auto-imagem e o amor-próprio" do eleitorado popular ${ }^{4}$. Convém lembrar que Lula é o primeiro presidente que viveu a experiência da miséria, o que não é irrelevante, dada a sensibilidade que demonstrou, uma vez na presidência, para a realidade dos miseráveis. Por isso, é plausível a suspeita de Francisco de Oliveira de que a eleição de 2006 comprove ter Lula se elevado "à condição de condottiere e de mito" 42 .

Oliveira acrescenta, entretanto, que é um tipo de liderança que "despolitiza a questão da pobreza e da desigualdade", o que leva o autor a questionar a natureza da hegemonia que estaria surgindo e a propor que ela agiria às avessas, isto é, para consolidar a "exploração desenfreada”, em lugar de minar o modelo superexplorador. À primeira vista, um lulismo despolitizante seria compatível com a "síndrome do Flamengo", hipótese formulada por Fábio Wanderley Reis para explicar a ascensão do MDB nos anos de 1970 e depois generalizada
[39] Holzhacker e Balbachevsky (op. cit., p. 289), reproduzem interessante estudo de Waldir Quadros, segundo o qual a massa de miseráveis teria caído de $38 \%$ em 2004 para $22 \%$ em 2005.

[40] Dados do IBGE citados por Araújo, op. cit., p. 145.

[41] Coimbra, op.cit., p.12.

[42] Oliveira. "Hegemonia às avessas", op. cit. 
[43] Reis, Fábio Wanderley. "Participação política”. Valor, 07/07/2008.

[44] O fato de o Eseb-20o6 ter ido a campo em dezembro, nove meses depois da pesquisa realizada pela Fundação Perseu Abramo (FPA) que consta do Quadro 1, não chega a constituir explicação para a diferença, pois nova rodada da FPA, em novembro de 2006 , encontrou uma diminuição pouco significativa da esquerda (de $26 \%$ em março para $23 \%$ em novembro) e uma estabilidade nas demais posições, inclusive no número dos que não sabiam se localizar (16\%).

[45] Carreirão. "Identificação ideológica, partidos e voto na eleição presidencial de 2006 ". Opinão Pública, vol. $13, \mathrm{n}^{\circ} 2$, nov. 2007 , p. 332 .

[46] Holzhacker e Balbachevsky, op. cit., p.304. como visão estrutural da política brasileira. Esse ponto de vista sustenta que um eleitorado de baixa escolaridade terá necessariamente que orientar-se por "imagens toscas" 43 , não se devendo esperar que ele esteja informado das orientações substantivas adotadas pelos atores nem que se guie por elas. Da mesma maneira que o voto popular no MDB não simbolizava, para espanto do senso comum, rejeição ao governo militar, o voto em Lula não representaria qualquer tipo de opção ideológica, antes pelo contrário, seria fruto de uma desideologização. As opções populares, regidas por mecanismos de identificação acionada por imagens difusas, nada expressariam de substantivo.

Esse esquema interpretativo foi relançado pelo Estudo Eleitoral Brasileiro (Eseb) que, em dezembro de 2006 , detectou declínio do apoio à esquerda quando comparado a 2002 (de 25,7\% para 9\%). O resultado do Eseb-2006, discrepante do encontrado pelas pesquisas resumidas no Quadro 1, as quais indicam uma estabilidade das preferências ideológicas ${ }^{44}$, foi acompanhado de um aumento equivalente do número de entrevistados que não sabia se posicionar na escala (de 23,2\% para 41,8\%). O Eseb-2002 já encontrava à direita um número dez pontos percentuais menor de eleitores do que a Criterium-2002 (28\% contra 39\%), sendo em compensação sete pontos percentuais maior a quantidade de entrevistados que não se classificavam na escala (23\% no Eseb-2002 contra 16\% na Criterium-2002). Ou seja, aparentemente o Eseb-2006 acentuou uma tendência já existente no Eseb-2002 (a de detectar um número superior de eleitores que não sabem se colocar no espectro ideológico)e, por caminhos diversos, chegou a uma proporção entre esquerda e direita mais próxima à das demais pesquisas, embora no conjunto continue a ressaltar o número muito superior de entrevistados que não sabem se localizar na escala: 41,8\% no Eseb-2006 contra 16\% da pesquisa da Fundação Perseu Abramo de novembro de 2006.

$\mathrm{O}$ aumento dos que não se classificavam na escala registrado pelo Eseb-2006 foi entendido por Carreirão como corroboração de que "após o primeiro mandato do presidente Lula ocorreu", na percepção dos eleitores brasileiros, "uma diluição das diferenças ideológicas entre os partidos (e lideranças políticas)" 45 . Conclusão semelhante à de Holzhacker e Balbachevsky, segundo as quais ocorrera "um esvaziamento da dimensão ideológica e do confronto de classes para explicar a vitória de Lula nas eleições de 2006" 46 . Nessa visão, é como se, depois do primeiro mandato de Lula, uma parte dos eleitores localizados à esquerda passasse a seguir o caminho já antes trilhado por cerca de $e^{1 / 4}$ dos eleitores, e deixasse de saber como se classificar na escala ideológica, retirando desta a influência que antes pudesse ter.

Se de um lado teria havido perda de substância ideológica, Carreirão sustenta que os "sentimentos partidários", a saber, tanto a 
preferência como a rejeição a determinado partido, "mostraram-se associados à decisão do voto". Pergunta ele, então, se estaríamos diante do que havia sido previsto por Fábio Wanderley Reis e Mônica Mata Machado de Castro em 1992 quando, inspirados pela noção de "síndrome do Flamengo", previam, em artigo que analisava dados colhidos no começo da reestruturação partidária (1982), que decantada a nova configuração se divisariam novamente "as linhas básicas de clivagem", com uma sigla adquirindo "a imagem de partido dos pobres — ou dos trabalhadores, desde que esta expressão seja tomada de maneira suficientemente difusa para tornar-se equivalente àquela" 47 . Nessescript,o PT estaria agora substituindo o MDB, tanto na falta de conteúdo como na capacidade de reter a lealdade popular.

Hunter e Power, contudo, detectam sinais de que, na eleição de 2006, o PT não acompanhou Lula em sua troca de base. Lula teria deixado um eleitorado tipicamente urbano e escolarizado por um francamente popular, mas o mesmo não teria ocorrido com o PT.

A tendência do apoio ao partido na Câmara dos Deputados, comparado ao de Lula,écada vez mais incongruente. Enquanto Lulafez impressionantes avanços nas regiões mais atrasadas do país (os grotões, o mais duradouro calcanhar de Aquiles do PT), a fortaleza do partido continua a ser a área mais urbana e industrializada do Brasil 48 .

Em outras palavras, Lula foi mais sufragado quanto menor o IDH do Estado, mas a votação da bancada federal do PT manteve-se associada aos de maior IDH49. Em conseqüência, Lula teve particular sucesso no Nordeste e no Norte, ao passo que a votação do PT continuou relevante no Sudeste e no Sul. Por isso, Lula teria crescido entre o primeiro turno de 2002 e o de 2006 , passando de $46,6 \%$ para $48,6 \%$ dos votos válidos, enquanto a bancada federal petista caiu, de 91 para 83 eleitos $^{50}$.

A desconexão entre as bases do lulismo e as do petismo em 2006 pode significar que entrou em cena uma força nova, constituída por Lula à frente de uma fração de classe antes caudatária dos partidos da ordem e que, mais do que um efeito geral de desideologização e despolitização, indicava a emergência de outra orientação ideológica, que antes não estava posta no tabuleiro. Parece-nos que o lulismo, ao executar o programa de combate à desigualdade dentro da ordem, confeccionou nova via ideológica, com a união de bandeiras que não pareciam combinar.

A "continuidade do governo Lula com o governo FHC" na política macroeconômica - "baseada em três pilares: metas de inflação, câmbio flutuante e superávit primário nas contas públicas" ${ }^{1}$ — foi uma decisão política e ideológica. A elevação do superávit primário para 4,25\% do PIB, a concessão de independência operacional ao Banco
[47] Reis, FábioWanderleye Castro,e Mônica Mata Machado de. "Regiões, classe e ideologia no processo eleitoral brasileiro". Lua Nova, n $^{\circ}$ 6, 1992 , p. 131.

[48] Hunter e Power, op. cit., p. 8, trad. minha.

[49] Ibidem, p. 11 .

50. Ibidem, p.7.

[51] Araújo, op.cit., p. 75 . 
[52] Diretório Nacional do Partido dos Trabalhadores. "Concepção e diretrizes do programa de governo do PT para o Brasil", mar. 2002, pp. 20, 21 e 25 .
Central, que teve à sua frente um deputado federal eleito pelo PSDB com autonomia para determinar a taxa de juros, e a inexistência de controle sobre a entrada e a saída de capitais foram o modo encontrado para assegurar um elemento vital na conquista do apoio dos mais pobres: a manutenção da ordem.

Nossa hipótese é de que o governo se afastou de aspectos do programa de esquerda adotado pelo PT até o final de 2001, o qual criticava "a estabilidade de preços [...] alcançada com o sacrifício de outros objetivos relevantes, como o crescimento econômico", a abolição das "restrições ao movimento de capitais" e a Lei de Responsabilidade Fiscal por tolher "elementos importantes de autonomia dos entes federados, engessando, em alguns casos, os investimentos em políticas sociais" 52 , com a finalidade de impedir que uma reação do capital, voltada para criar dificuldades à mudança, provocasse instabilidade econômica e atingisse os excluídos das relações econômicas formais. Para trabalhadores com carteira assinada e organização sindical, a luta de classes em regime democrático oferece alternativas de autodefesa em momentos de instabilidade. Mas os que não podem lançar mão de instrumentos equivalentes, por não estarem organizados, seriam vulneráveis à propaganda oposicionista contra a "bagunça”.

Os anos FHC legaram um pacto com a burguesia que envolvia juros altos, liberdade de movimento dos capitais e contenção do gasto público. Se é verdade que o desemprego resultante inviabilizou o sonho pessedebista de vinte anos seguidos no poder (a perene quimera da presidência rooseveltiana), também é certo que o Real conquistara o eleitorado popular. Se nossa hipótese estiver correta, a continuidade do pacote "FHC" foi posta pela burguesia como condição de não haver "guerra" de classes e conseqüente risco de o governo ser acusado de destruir o Real.

Não é aqui o lugar para discutir se, acaso fosse tentada outra via, implicando algum grau de confronto com o capital, teria sido exeqüivel impor outra correlação de forças. O fato é que o governo preferiu conter a subida dos preços pelo caminho ortodoxo, aprofundando as receitas neoliberais, como foi o caso da combinação de corte no gasto público e aumento de juros em 2003. Com a redução da demanda e a volta dos dólares que haviam fugido com medo de um governo de esquerda, a inflação, que tinha alcançado a marca de $12,53 \%$ em 2002, foi reduzida a 9,3\% em 2003, 7,6\% em 2004 e 5,69\% em 2005 . O presidente vocalizou, então, o discurso conservador de que o seu governo não adotaria qualquer plano que pusesse em risco a estabilidade, preferindo administrar a economia com a "prudência de uma dona de casa". Se ao fazê-lo estabelecia um hiato em relação ao seu próprio partido, em troca criava uma ponte ideológica com os mais pobres. 
Porém se tivesse ficado nisso, só repetiria o relativo sucesso do primeiro mandato de $\mathrm{FHC}$, o qual não provocou um realinhamento do eleitorado, apesar de emplacar o discurso de que "tudoé um processo", equivalente tucano da "prudência da dona de casa". O pulo do gato de Lula foi, sobre o pano de fundo da ortodoxia econômica, construir uma substantiva política de promoção do mercado interno voltado aos menos favorecidos, a qual, somada à manutenção da estabilidade, corresponde nada mais nada menos que à realização de um completo programa de classe. Não o da classe trabalhadora organizada, cujo movimento iniciado no final da década de 1970 tinha por bandeira a "ruptura com o atual modelo econômico" 53 , mas à fração de classe que Paul Singer chamou de "subproletariado" ao analisar a estrutura social do Brasil no início dos anos de 1980.

Subproletários são aqueles que "oferecem a sua força de trabalho no mercado sem encontrar quem esteja disposto a adquiri-la por um preço que assegure sua reprodução em condições normais" 54 . Estão nessa categoria "empregados domésticos, assalariados de pequenos produtores diretos e trabalhadores destituídos das condições mínimas de participação na luta de classes" 55 . Para encontrar uma maneira de quantificá-los, Singer usou informações sobre ocupação e renda fornecidas pela PNAD de 1976, concluindo que seria razoável considerar subproletários os que tinham renda de até um salário mínimo per capita e metade dos que tinham renda de até dois salários mínimos per capita ${ }^{56}$. De acordo com esse critério, 63\% do proletariado era constituído por subproletários 57 . Em números absolutos, significava dizer que dos 29,5 milhões de proletários existentes no Brasil naquela época, 18,6 milhões faziam parte da fração subproletária da classe. Dos outros participantes da População Economicamente Ativa (PEA), 8 milhões seriam pequeno-burgueses e 1,3 milhão, burgueses $^{5}$. Em outras palavras, o subproletariado constituía $48 \%$ da PEA.

Apesar de não dispormos de uma atualização para o trabalho realizado por Singer, a lógica permite supor que os processos de aumento da produtividade, desindustrialização, desemprego estrutural, subemprego, precarização do trabalho em geral e crescimento da pobreza que acompanharam a implantação do neoliberalismo nos anos de 1990 tenham, no mínimo, mantido a proporção de subproletários no proletariado em geral. Vai nessa direção Oliveira, em texto originalmente publicado em 2003, quando afirma que

[...] o trabalho sem-formas inclui mais de $50 \%$ da força de trabalho, e o desemprego aberto saltou de $4 \%$ no começo dos anos 1990 para $8 \%$ em 2002, segundo a metodologia conservadora do IBGE; entre o desemprego e o trabalho sem-formas, transita, entre o azar e a sorte, $60 \%$ da força de trabalho brasileira59.
[53] Ibidem, p.15.

[54] Singer, P. Dominação e desigualdade.São Paulo:Paz eTerra,1981, p.22.

[55] Ibidem, p. 83 .

[56] Ibidem, p. 86.

[57] Ibidem, p.129.

[58] Ibidem, p. 108.

[59] Oliveira. "Política numa era de indeterminação: opacidade e encantamento". In: Oliveira, Francisco de e Rizek, C.A era da indeterminação. São Paulo: Boitempo, 2007, p. 34 . 
[6o] Singer, P. Repartição da renda: pobres e ricos sob o regime militar. Rio de Janeiro: Jorge Zahar, 1985, p. 42.

[61] "Segundo o Datafolha, os eleitores com renda de até dois salários mínimos representam $47 \%$ do total", publicou a Folha de S. Paulo em o8/10/2006.
[62] Venturi, Gustavo. "Esquerda ou direita?". Teoria e Debate, $\mathrm{n}^{\circ} 75$, jan.-fev. 2008, p. 39. As posições no espectro ideológico foram agregadas em 1 e 2 = esquerda; 3,4 e 5 = centro; 5 e 6 = direita. Dados de pesquisa da Fundação Perseu Abramo realizada com uma amostra nacional de 2.400 entrevistados em novembro de 2006 .

[63] Idem, ibidem.
Em 1980, 44\% das famílias no Brasil tinham renda de até dois salários mínimos ${ }^{60}$ e um quarto de século depois, $47 \%$ do eleitorado estava nessa faixa de renda ${ }^{61}$.

Em virtude de seu tamanho, o subproletariado encontra-se no centro da equação eleitoral brasileira, e seu coração está no Nordeste. Não somente porque nessa região empobrecida, queé a segunda mais populosa do país, habitam boa parte dos subproletários, mas também porque dela irradiam aqueles que buscam oportunidade no centro capitalista, o Sudeste. Nucleado no Nordeste, onde conta com elementos biográficos, mas estendendo-se para o conjunto do país, o lulismo, segundo indicam os dados eleitorais de 2006, pode ter fincado raízes duradouras no subproletariado brasileiro.

\section{E AGORA, JOSÉ?}

Comovimos, a persistência do que poderíamos chamarde "conservadorismo popular" marca a distribuição das preferências ideológicas no Brasil pós-redemocratização, com a direita reunindo sempre cerca de $50 \%$ mais eleitores do que a esquerda. Gustavo Venturi mostra que a pendência para a direita do eleitorado de menor escolaridade (que está associada à renda), já observada em 1989, continuava presente quase duas décadas depois. Em 2006, enquanto os eleitores de escolaridade superior dividiam-se por igual entre os campos da esquerda ( $31 \%)$, do centro $(32 \%)$ e da direita ( $31 \%)$, entre os que freqüentaram até a quarta série do ensino fundamental, a direita tinha $44 \%$ de preferência, mais do que triplo de adesão que tinha a esquerda (16\%) e o centro $(15 \%)^{62}$. Essa é a explicação para a conclusão de Venturi: "Passadas mais de duas décadas de democracia, a construção de uma hegemonia político-cultural identificada como de esquerda não avançou"63. Em que pese o sucesso do PT e da CUT, a esquerda não foi capaz de dar a direção ao subproletariado, uma fração de classe particularmente difícil de organizar. O subproletariado, a menos que organizado por movimentos como o MST, tende a ser politicamente constituído desde cima, como descobriu Marx a respeito dos camponeses da França em 1848. Atomizados pela sua inserção no sistema produtivo, necessitam de alguém que possa, desde o alto, receber a projeção de suas aspirações.

Buscamos aqui mostrar que, na ausência de um avanço da esquerda, o primeiro mandato de Lula terminou por encontrar outra via de acesso ao subproletariado, amoldando-se a ele, mais do que o modelando, porém, ao mesmo tempo, constituindo-o como ator político. Isso implicou um realinhamento do eleitorado e a emergência de uma força nova, o lulismo, tornando necessário um reposicionamento dos demais segmentos. 


\begin{tabular}{|c|c|c|c|c|}
\hline & Esquerda & Centro & Direita & Total \\
\hline Lula & $66 \%$ & $52 \%$ & $50 \%$ & $53 \%$ \\
\hline Serra & $10 \%$ & $17 \%$ & $19 \%$ & $16 \%$ \\
\hline Garotinho & $9 \%$ & $12 \%$ & $13 \%$ & $12 \%$ \\
\hline Ciro & $5 \%$ & $11 \%$ & $7 \%$ & $8 \%$ \\
\hline Nenhum/BR/Nulo/Não sabe/Não opinou & $11 \%$ & $8 \%$ & $9 \%$ & $11 \%$ \\
\hline Total & $100 \%$ & $100 \%$ & $100 \%$ & $100 \%$ \\
\hline
\end{tabular}

Obs.: As posições na escala de 1 a 7 foram assim agrupadas: esquerda = 1 e 2; centro = 3, 4 e 5; direita = 6 e 7 .

Fonte: Fundação Perseu Abramo. Pesquisa com amostra nacional de 2291 eleitores, realizada em novembro de 2002.

TABELA 7

Voto no primeiro turno de 2006 por localização no espectro ideológico

\begin{tabular}{|c|c|c|c|c|}
\hline & Esquerda & Centro & Direita & Total \\
\hline Lula & $62 \%$ & $49 \%$ & $63 \%$ & $55 \%$ \\
\hline Alckmin & $19 \%$ & $28 \%$ & $20 \%$ & $24 \%$ \\
\hline Heloísa Helena & $5 \%$ & $5 \%$ & $3 \%$ & $4 \%$ \\
\hline Cristovam & $1 \%$ & $3 \%$ & $1 \%$ & $2 \%$ \\
\hline Outros/BR/Nulo/Não lembra/Não votou/Não respondeu & $14 \%$ & $16 \%$ & $12 \%$ & $15 \%$ \\
\hline Total & $100 \%$ & $100 \%$ & $100 \%$ & $100 \%$ \\
\hline
\end{tabular}

Obs.: As posições na escala de 1 a 7 foram assim agrupadas: esquerda = 1 e 2; centro = 3, 4 e 5; direita $=6$ e 7 .

Fonte:Fundação Perseu Abramo.Pesquisa com amostra nacional de 2400 eleitores, realizada em novembro de 2006.

O discurso de Lula em defesa da estabilidade tirou a plataforma a partir da qual o centro mobilizava os mais pobres, sobrando-lhe apenas o recurso às denúncias de corrupção, assunto limitado à classe média. Isso implicou um aumento dos votos para Lula à direita, como se pode verificar na comparação entre as Tabelas 6 e 7, limitando ao centro a base da oposição. Diante da dificuldade de ganhar eleições presidenciais só com a classe média, os oposicionistas não sabem para aonde ir.

Em 2002, embora os índices de Lula tivessem aumentado em todos os segmentos, a tendência permanecia a de 1989: aumento da intenção de voto conforme se caminhava da direita para a esquerda. Em uma situação como essa, o centro ainda tinha chances de recuperar, adiante, o eleitorado de direita e sonhar com uma volta ao Planalto, sobretudo se a ordem estivesse ameaçada ${ }^{64}$. Em 2006,

[64] Acredito que em virtude da existência de uma "direita popular", o centro é a posição mais associada à classe média conservadora no Brasil e não a direita, como ocorre em outras formações sociais. 
[65] Oliveira, "Hegemonia às avessas", op.cit. como reflexo do realinhamento, o voto em Lula sofre uma mudança ideológica: aumenta em direção aos extremos, tanto esquerdo como direito, e cai em direção ao centro (Tabela 7). O fato de Lula receber votos à esquerda e à direita de modo equivalente seria o reflexo do realinhamento em curso, a partir do qual Lula passa a representar uma opção nova, que mistura elementos de esquerda e de direita, contra uma alternativa de classe média organizada em torno de uma formulação de centro.

Para a esquerda, fica a tarefa de redefinir o discurso de classe à sombra de uma liderança popular no sentido pleno da palavra. Não será surpresa se tiver que se defrontar, outra vez, com a impregnação de imagens que marcaram a era Vargas. Tem razão Francisco de Oliveira quando afirma que há "um fenômeno novo" em curso, que "não é nada parecido com qualquer das práticas de dominação exercidas ao longo da existência do Brasil"65 (embora não seja a "hegemonia às avessas" e sim, talvez, uma efetiva representação do subproletariado), mas há sintomas de que, como soe acontecer na história, o novo possa buscar no passado a linguagem em que se expressar, como lembra Marx nas primeiras páginas de $\mathrm{O}_{1} 8$ Brumário.

O popular que havia ficado fora de moda, seja pela retórica da modernização, ao centro, seja pelo discurso de classe, à esquerda, está de volta. Diferentemente da experiência peessedebista, o "Real de Lula" veio acompanhado de uma mensagem que faz sentido para os de menor renda: pela primeira vez o Estado brasileiro olha para os mais frágeis e, portanto, se popularizou. Essa é a razão pela qual o presidente insiste que "nunca na história deste país... etc. etc.". Irritados, os supostos "formadores de opinião" não percebem que Lula não está se dirigindo a eles e insistem na tecla de que a história não começou com Lula, o queéverdade, mas ouvido vários degraus abaixo, o bordão adquire outro sentido.

O relativo desinteresse de Lula pelos "formadores de opinião" significa que o realinhamento tirou centralidade dos estratos médios, que eram mais importantes no alinhamento anterior. Nele, a esquerda organizava segmentos baixos e médios da "classe média", notadamente operários industriais e servidores públicos, em torno de uma ideologia de esquerda, isto é, do discurso de classe. O centro agregava as classes médias ao redor da modernização do capitalismo e mobilizava o subproletariado contra a esquerda nos momentos cruciais.Assim, o conflito político geral era filtrado pelo debate entre os setores médios.

À medida que passou a ser sustentado pela base subproletária, Lula obteve uma autonomia bonapartista (sem qualquer conotação militar). Com ela, criou um ponto de fuga para a luta de classes, que começou a ser arbitrada desde cima ao sabor da correlação de forças. 
Se a reforma da previdência, que tirava benefícios do servidor público, passou, a reforma trabalhista, que visava tirar direitos dos assalariados, foi adiada sine die, e assim por diante.

Árbitro acima das classes, o lulismo não precisa afirmar que o povo alcançou o poder ou que "os dominados comandam a política", como na formulação que Oliveira foi buscar na África do Sul pós-apartheid ${ }^{66}$. Ao incorporar tanto pontos de vista conservadores, principalmente o de que a conquista da igualdade não requer um movimento de classe auto-organizado que rompa a ordem capitalista, como progressistas, a saber, o de que um Estado fortalecido tem o dever de proteger os mais pobres, independentemente do desejo do capital, ele achou em símbolos dos anos de 1950 a gramática necessária. A noção antiga de que o conflito entre um Estado popular e elites antipovo se sobrepunha a todos os outros poderá cair como uma luva para o próximo período. Agora enunciada por um nordestino saído das entranhas do subproletariado, ganha uma legitimidade que talvez não tenha tido na boca de estancieiros gaúchos. Por isso, se a hipótese do realinhamento se confirmar, o debate sobre o populismo ressurgirá das camadas pré-sal anteriores a 1964, em que parecia destinado a dormir para todo o sempre.

ANDRÉ SINGERé professor do Departamento de Ciência Política da Universidade de São Paulo.
[66] Ibidem.

Recebido para publicação

em 19 de setembro de 2009 .

NOVOS ESTUDOS

CEBRAP

85 , novembro 2009

pp. $83-102$ 